J.Univ.Ruhuna 2013 1(1): 1-2

Volume 1 Number 1, March 2013

ISSN 2345-9387

\title{
EDITORIAL
}

\section{The importance of improving intuition for research in young academics}

The word intuition has derived from the Latin term "intueri." Generally, intueri in Latin means the ability to acquire knowledge about things without reasoning. The intuition implies something deeper than simple and superficial observation on something and is best described as apperception or the ability to "take hold of" knowledge in one glance. According to the Webster's Unabridged Dictionary, intuition is described as "the immediate knowing or learning of something without the conscious use of reasoning; instantaneous apperception". Intuition is very important for young academics to become good researchers. Perhaps you may have observed that good researchers make sudden changes in their researches. Such sudden changes of direction in research can be caused by intuition. Intuition leads to success in the research when the basic idea is followed with extreme diligence, consequence and perseverance. If you are a good researcher with high intuitive capacity, at the end of your experiment, research and intuition should be tied together. This is because a good researcher continues to work hard with uninterrupted commitment on one side and uses intuition as a source of energy for perseverance and stamina.

All human beings are born with different levels of intelligence quotient (IQ) and intuitive quotient (InQ). Somebody's IQ represents his/her ability to provide predetermined correct answers to questions focusing on a variety of skills. On the contrary, InQ reflects somebody's ability to go inward, react to a variety of intuitive skills, recognize relations, communicate nontraditionally, and tap the wisdom on a variety of analytical skills. As a conventional researcher one can carry out the research in the traditional frame of research viz. design of experiment, conducting the experiment, making observations, statistical analysis and interpretation. This traditional process of conducting research needs lots of resources as well as time. But, as academic researchers we may have to make decisions in the face of severe time constraints, incomplete information, high pressure and unclear goals.

Gary Klein (2004) in his book "The Power of Intuition" has mentioned that firefighters have no time to compare multiple options and with the incomplete information they receive they simulate the situation and execute through intuition. Klein's findings are contradicted to the formal decisionmaking strategies of a researcher. Therefore, some researchers are against the use of intuition. They believe it could mislead and instead want to consider multiple options and compare them across multiple dimensions in a design experiment. Perhaps you may think, in terms of speed of the actions to be executed, research is the opposite of firefighting. For a firefighter, the situation is live and demands immediate action, due to high risk and neediness of immediate feedback about success. Research, on the other hand, is a slow process, with very little riding on decisions made on the spur of the moment and very rare opportunities for instantaneous feedback.

However, in recent years, many researchers have realized the infeasibility of comparing multiple options as well as the advantages of strengthening intuition in order to pick good first options. This is important in situations where either the availability of unambiguous and clear information is insufficient, or the effort needed to process all the information is impracticable due to various physical, financial, human and time constraints. This is more common when dealing with humanities and social sciences research. In such situation, the intuition helps the researcher to make correct or most appropriate decisions. But, one should not forget that beginners alone cannot work with intuition in research. Practice improves the intuition. 
Klein in his book "The Power of Intuition" identifies two aspects to improve the intuition in research: frequency of exposure to situations and the feedback on the model or the option used. Frequency alone is not enough. Therefore, young academics should first use the conventional research methodology frequently and listen to feedbacks on their models from senior academics before going to use intuition in their research modeling. Thus, the best practice for young academics is to undergo an apprenticeship under the guidance of senior academic researchers and to observe how these seniors use intuition in their research activities. Doing a Ph.D. under a guide (a supervisor) is an apprenticeship. It is essential for young academics to read for Ph.D. if they really wish to become good researchers. Even after completing a

Gamini Senanayake

University of Ruhuna, Wellamadama,

Matara, Sri Lanka.

Correspondence: gmnsenanayake@yahoo.com
Ph.D., an academic is generally advised to work under guidance of a more experienced senior professor before fleshing it out totally on his/her own. Therefore, every academic researcher should try to improve his/her intuition in order to execute good research. For this, a young researcher needs to follow an apprenticeship under the guidance of a well experienced and research oriented senior academic.

\section{References}

1. The Power of Intuition: How to Use Your Gut Feelings to Make Better Decisions at Work, Gary Klein, Publisher: Crown Publishing Group (2004)

ISBN: 0385502893, 978-0385502894 